\title{
Wie Nierenfunktion und Sturzrisiko zusammenhängen
}

\author{
VON L. C. DUKAS
}

\section{Ein Mangel an D-Hormon geht mit einem erhöhten Sturzrisiko einher. Nicht immer lässt sich dieser Mangel durch die Gabe von Vitamin D beheben. Denn bei eingeschränkter Nierenfunktion, Diabetes oder Glukokortikoidtherapie ist der in den Nieren erfol- gende Umwandlungsschritt zum D-Hormon erheblich gestört.}

— Die herausragende Rolle des D-Hormons für den Knochenstoffwechsel und die Muskulatur ist wissenschaftlich vielfach untersucht worden und gesichert. Nach neuesten Erkenntnissen hat das D-Hormon (Calcitriol) einen ausgeprägten Einfluss auf die Muskulatur, deren Reaktionsfähigkeit und -schnelligkeit, auf die neurogene Muskelkoordination und das Gleichgewicht. Studien haben gezeigt, dass eine Therapie mit dem D-Hormon [1, 2] oder dem Analogon Alfacalcidol [3, 4, 5] sowohl Sturzereignisse als auch das Risiko für sturzbedingte Frakturen signifikant vermindert.

D-Hormon entsteht aus Vorläuferstufen und aus dem sog. „Vitamin D“ (Cholecalciferol). Der Begriff „Vitamin D“ ist falsch und entstand, als Struktur, Metabolismus und Wirkmechanismus des D-Hormons noch unbekannt waren. Die Unterscheidung zwischen Vitamin und Hormon ist jedoch von immenser Bedeutung: Im Gegensatz zu einem Vitaminmangel, wo eine einfache Substitution den Mangel behebt, kann ein Hormonmangel nicht unbedingt durch die Gabe von Vorläuferstufen behoben werden.

Wie aus Abbildung 1 ersichtlich ist der komplizierte Metabolismus von den Vorläuferstufen über das Cholecalciferol bis zum D-Hormon (Calci-

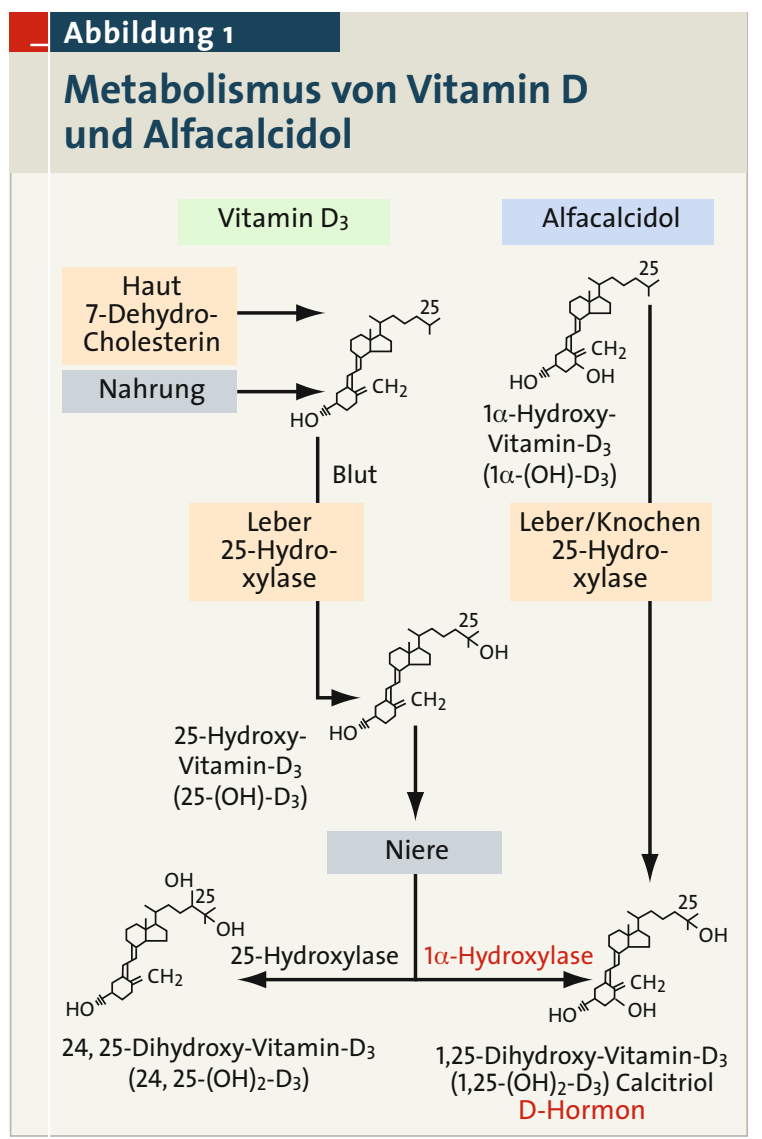

Die Verstoffwechselung von Vitamin $D_{3}$ in D-Hormon erfordert einen Hydroxylierungsschritt in den Nieren. Dieser Schritt entfällt bei Alfacalcidol.
Dr. med. L. C. Dukas, M. P. H.

Ambulatorium Wiesendamm, Basel

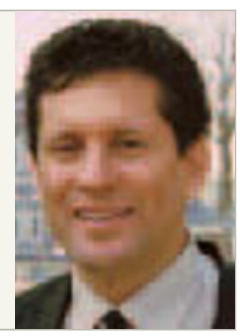

triol) abhängig von der Aktivität verschiedener Organsysteme. Der entscheidende letzte Schritt geschieht in den Nieren, wo Calcidiol in einer zweiten Hydroxylierung in das aktive D-Hormon umgewandelt wird. Dieser Schritt erfolgt in den proximalen Tubuli durch das Enzym $1 \alpha$-Hydroxylase.

\section{Verminderte D-Hormon-Synthese}

Die Aktivität der renalen $1 \alpha$-Hydroxylase ist abhängig von der Nierenfunktion. Wie unsere Studiengruppe zeigen konnte, kommt es schon bei einer Kreatinin-Clearance $\leq 65 \mathrm{ml} / \mathrm{min}$ trotz normaler Vitamin-D-Serum-Werte zu einer signifikanten Abnahme der D-Hormon-Serumwerte. Das heißt, dass ein D-Hormonmangel schon bei einer leicht reduzierten Nierenfunktion nicht durch eine Vitamin-D-Substitution behoben werden kann. Diese Erkenntnisse wurden durch unabhängige Studiengruppen bestätigt $[2,6]$. Andere Faktoren, die die Aktivität der renalen 1-alpha-Hydroxylase hemmen, sind ein Diabetes, eine Glukokortikoidtherapie sowie entzündliche und Autoimmunerkrankungen.

\section{Literatur beim Verfasser}

\section{Anschrift des Verfassers:}

Dr. med. Laurent C. Dukas, M. P. H.,

Ambulatorium Wiesendamm,

Wiesendamm 22, CH-4057 Basel 